Research Article

\title{
Designing a Data Warehouse for Earthquake Risk Assessment of Buildings: A Case Study for Healthcare Facilities
}

\author{
(D) Mert Özcan ${ }^{1}$, (D) Serhat Peker ${ }^{2}$ \\ ${ }^{1}$ Corresponding Author; Izmir Bakircay University, Department of Management Information Systems; \\ mert.ozcan@saglik.gov.tr; +90 3124718350 \\ ${ }^{2}$ Izmir Bakircay University, Department of Management Information Systems; serhat.peker@bakircay.edu.tr
}

Received 1 February 2021; Revised 16 March 2021 Accepted 24 March 2021; Published online 26 April 2021

\begin{abstract}
Since earthquake is one of the most dangerous natural phenomena, it is necessary to be prepared for the negative consequences of the earthquake in advance. It is very important that healthcare facilities must continue to provide service during and after an earthquake. Therefore, this study focuses on designing a data warehouse model for the earthquake risk assessment of healthcare facilities which are needed much more than other public buildings physically. The proposed design utilizes a fact constellation schema model and take a public legislation containing principles regarding identification of risky buildings. This solution can provide a repository for data regarding earthquake risk assessment from different operational systems and play a key role in supporting critical decisionmaking process.
\end{abstract}

Keywords: Data warehouse, data management, multidimensional data model, data mining, decision support systems, business intelligence and analytics

\section{Introduction}

Earthquake is one of the most dangerous natural disasters which causes not only damages to buildings but also a great number of deaths and injuries because of building collapses. Although it is not possible to prevent this natural phenomenon itself, various technological developments and approaches show that many of deaths and injuries are preventable. Turkey has been exposed to major and destructive earthquakes for centuries [1]. 92\% of the country is under the risk of earthquake, thus, the earthquake risks may affect the $95 \%$ of the population in the country. Although public authorities make legislative efforts, the quality of building stock in Turkey is not at the desired level for such disasters yet [2]. Because of that, earthquake is a critical threat for people living in this country. It is clear that, healthcare facilities have higher risks than other types of buildings due to their high importance [3]. Thus, assessing healthcare facilities is quite necessary for disaster preparedness process.

Turkey is among the top 10 OECD countries in terms of total physicians, hospitals number and hospital beds, etc. [4]. These rankings indicate that, Turkey has an important health infrastructure among the developing and developed countries. Health services are currently provided by over 65.000 healthcare facilities, including hospitals, family practice centers, clinics, laboratories, emergency medical service stations, etc. These healthcare facilities are constructed by Ministry of Health or used by renting. For instance, there are over 40.000 private clinics and family practice centers in Turkey, however the most of them are not constructed by Ministry of Health itself. On the other hand, approximately 650.000 healthcare professionals serve healthcare at such a large number of healthcare facilities [5]. Together with patients, millions of people are constantly served by these personnel in the healthcare facilities. However, there is insufficient evidence for the overall systematic assessment of these facilities in terms of earthquake preparedness. Therefore, a systematical perspective is considered to be needed for earthquake risk assessment of the healthcare facilities.

Risk assessment of buildings is a complex process which relies on a series of evaluation criteria with multiple parameters. To manage this process with massive amounts of data from various sources, a 
Özcan et al.

comprehensive data warehouse model is needed. Data Warehouse (DW) term can be defined as multidimensional databases that involve large amount of data [6]. Data warehouses have major features such as integrated, subject-oriented, time variant and nonvolatile support for decision making [7]. It provides architectural tools for decision makers in order to organize, understand and use their data to make strategic decisions [8]. In addition to these, many enterprise information systems utilize data warehouses to enhance business intelligence and analytics by implementing diverse data mining techniques [9].

Based on the aforementioned benefits, data warehouses can become the repository for complex process of earthquake risk assessment for buildings. Therefore decision makers can make faster and better decisions on urgent improvement works for earthquake countermeasures. In this context, the study aims to design a data warehouse model for earthquake risk assessment of healthcare facilities in Turkey. A fact constellation schema model is devised based on a public legislation.

The rest of the paper is organized as follows: Section 2 provides an overview of the background of data warehouses and related works. Section 3 presents the proposed data warehouse design with details of the methodology and sample queries. Finally, Section 4 presents concluding remarks and future work directions.

\section{Background}

\subsection{Data Warehouse}

Data warehouses have been almost indispensable for decision support systems, data mining, business analysis, forecasting and business intelligence since "Business Data Warehouse" term took part in the literature in 1988 [10]. Data warehouses are data management systems that are designed for specific purposes. By using specific queries and analyzing tools in a more efficient way, data warehouses provide great convenience both for IT professionals and end users. One of the most important features of data warehouses for business intelligence that integrated and purposive data are stored rather than detailed and individual ones [11]. Therefore, it is possible to have higher performance, safer, more reliable, more retrievable and more manageable systems.

Success of the selected data warehouses approach relates how data modeling techniques are applied. As a logical design approach, dimensional models are usually chosen for data warehouses. As an alternative approach to traditional entity relationship model, dimensional models have more advantages for decision supports. In this approach, there are fact tables and dimension tables. Fact tables have numerical and additive measurements for specific requirements of a business. Dimension tables are created for defining business entities. Dimension tables are linked with fact table with their primary keys [12]. By this approach, it is aimed to obtain easier structures for end users and to have more efficient queries. For this reason, less tables and relations are preferred with less joins in queries [13].

The most demanded and well-known methods for applying multidimensional modeling are star schema, snowflake schema and fact constellation schema. Star schema is created by linking a series of dimensional tables which generally consist of embedded hierarchies around a fact table. Star schema has one large central table which is called fact table. The fact table is linked with smaller dimension tables. The dimension tables surround the fact table. The fact table may be linked with numerous dimension tables by one to many relationships in star schema [13]. In snowflake schema, dimension tables are linked to another dimension table without being linked directly to the fact table [14], [15]. Thus, snowflake schema differs from star schema with including more hierarchies rather than only one hierarchy. The third dimensional model which has more than one fact table is called fact constellation schema. This schema can be considered as a combination of two or more star schemas. One of the typical features of the fact constellation schema is flexibility. The fact constellation schema has more than one fact tables. These fact tables share several dimension tables. Although modeling process is more complex than the other models, the complexity brings to ability to have more accurate outputs [16]. This model is also called galaxy model in the literature. 
Özcan et al.

\subsection{Related Work}

Before starting the design process, different dimensional data warehouses and their design aspects were reviewed. The review on current literature has showed that the data warehouses are raising their own significance by creating more effective decision-making tools in order to support end user queries.

Different solutions have been proposed so far for data warehouses, most of them based on disaster management. Asghar et al. [17] introduced a business intelligence system that links dimensions of business intelligence and processes together, for providing a good decision support, for disaster management organization as a case study. Their data warehouse model has three main fact tables and two dimensions tables. According to the validated experimental results of the study, proposed business intelligence system performs for decisions on disaster management efficiently.

Panrungsri and Sangiamkul [18] applied a business intelligence model for disaster management area by applying a case study. They design and develop a data warehouse with multidimensional model for severity analysis disasters in risk areas. The aim of the study is to have a business intelligence concept by improving data quality and exposing to better decision making for disaster management. It is mentioned that the proposed data model with fact constellation schema can enable agility capacity for business intelligence technology in disaster management processes.

Permana et al. [19] has recently proposed a date warehouse for disaster management. The proposed data warehouse in this research was designed as a snowflake schema based on information about kind of disaster, place and the effect of disaster. The feature of Online Analytical Processing (OLAP) for disaster report can be a significant tool for decision makers in order to manage future risk of the disasters. In another recent study, a web-based assessment software has been developed in order to describe risk priorities of concrete buildings [20]. In this study, a rapid assessment method issued by the Ministry of Environment and Urbanization was employed.

Sarı and Türk [21] has built a database to investigate building damages caused by earthquakes in Turkey. They measured the building qualities and illustrated in proposed Geographical Information System (GIS). The aim of this study was to determine the earthquake risk levels of buildings in selected area. Building data were created in accordance with the Federal Emergency Management Agency (FEMA) approach in this research. The data were obtained from the municipality and transferred to GIS environment. Then the vulnerability and quality levels of buildings were determined in Sivas Municipality City Information System in a possible earthquake.

Considering the studies mentioned above, although especially in recent years, several research studies have relied on many different data models in disaster management, there has not been any prior study that mainly focuses on building a comprehensive data warehouse model for earthquake risk assessment. In this regard, designing a data warehouse focusing on earthquake risk assessment of buildings can significantly contribute to relevant literature.

\section{Building Data Warehouse}

This study is based on principles of identification of risky buildings which are published by Turkish Environment and Urban Ministry [22]. This legislation includes calculations to classify buildings in terms of earthquake risk levels by considering certain parameters. These parameters affecting the risk assessment of buildings are as follows:

- $\quad$ Structural system type;

- Number of floors;

- Visual quality;

- Soft storey / weak storey;

- Vertical irregularity;

- Heavy overhang;

- Torsion effect;

- Short column effect;

- Construction Regularity; 
Özcan et al.

- Ground slope;

- Earthquake danger zone.

Each building is assessed according to three sub assessment calculations which are called as negativity, ground system and structural system. For negativity calculation, each building is given a value according to certain eight parameters as shown in Table 1. Buildings are given 0,1 or 2 value according to the negativity parameter detection case. Supposing that; if the visual quality of the building is determined as 'good', then the negativity value of "Visual Quality" parameter will be 0 . If it is determined as 'moderate' or 'poor', then the parameter value will be 1 or 2 , respectively. As a result of negativity parameter assessment, each building will have eight parameter values for eight negativity parameters on aggregate.

Table 1 Negativity Parameter Values (Ni)

\begin{tabular}{cccccc}
\hline & & \multicolumn{2}{c}{ Case 1 } & \multicolumn{2}{c}{ Case 2 } \\
\cline { 3 - 6 } No & Negativity & $\begin{array}{c}\text { Parameter } \\
\text { Petection }\end{array}$ & $\begin{array}{c}\text { Parameter } \\
\text { Value ( O }\end{array}$ & $\begin{array}{c}\text { Parameter } \\
\text { Detection }\end{array}$ & $\begin{array}{c}\text { Parameter } \\
\text { Value ( O }\end{array}$ \\
\hline 1 & Visual Quality & Good & 0 & Moderate (Poor) & $1(2)$ \\
2 & Soft Storey & No & 0 & Yes & 1 \\
3 & Vertical Irregularity & No & 0 & Yes & 1 \\
4 & Heavy Overhang & No & 0 & Yes & 1 \\
5 & Torsion Effect & No & 0 & Yes & 1 \\
6 & Short Column Effect & No & 0 & Yes & 1 \\
7 & Construction Regularity & Detached & 0 & Attached & 1 \\
8 & Ground Slope & No & 0 & Yes & 1 \\
\hline
\end{tabular}

Each negativity parameter has negativity parameter score according to the number of floors of the building as shown in Table 2. For instance, if a building has 5 floors, then the negativity score of visual quality will be measured as -25 for that building. To put it another example; if a building has 7 floors, then the negativity score of torsion effect will be -10 for that building.

Table 2 Negativity Parameter Scores (NPi)

\begin{tabular}{|c|c|c|c|c|c|c|c|c|c|c|c|}
\hline \multirow{3}{*}{$\begin{array}{c}\text { Number } \\
\text { of } \\
\text { Floors }\end{array}$} & \multirow{3}{*}{$\begin{array}{l}\text { Visual } \\
\text { Quality }\end{array}$} & \multirow{3}{*}{$\begin{array}{l}\text { Soft } \\
\text { Storey }\end{array}$} & \multirow{3}{*}{$\begin{array}{l}\text { Vertical Ir- } \\
\text { regularity }\end{array}$} & \multirow{3}{*}{$\begin{array}{c}\text { Heavy } \\
\text { Overhang }\end{array}$} & \multirow{3}{*}{$\begin{array}{c}\text { Torsion } \\
\text { Effect }\end{array}$} & \multirow{3}{*}{$\begin{array}{l}\text { Short } \\
\text { Column } \\
\text { Effect }\end{array}$} & \multicolumn{4}{|c|}{ Construction Regularity } & \multirow{3}{*}{$\begin{array}{c}\text { Ground } \\
\text { Slope }\end{array}$} \\
\hline & & & & & & & \multicolumn{2}{|c|}{ Same } & \multicolumn{2}{|c|}{ Different } & \\
\hline & & & & & & & Center & Side & Center & Side & \\
\hline 1,2 & -10 & -10 & -5 & -10 & -5 & -5 & 0 & -10 & -5 & -15 & -3 \\
\hline 3 & -10 & -20 & -10 & -20 & -10 & -5 & 0 & -10 & -5 & -15 & -3 \\
\hline 4 & -15 & -30 & -15 & -30 & -10 & -5 & 0 & -10 & -5 & -15 & -3 \\
\hline 5 & -25 & -30 & -15 & -30 & -10 & -5 & 0 & -10 & -5 & -15 & -3 \\
\hline 6,7 & -30 & -30 & -15 & -30 & -10 & -5 & 0 & -10 & -5 & -15 & -3 \\
\hline
\end{tabular}

Overall, Ground System Score (GSS) and Structural System Score (SSS) are measured for each building, as shown in Table 3. Supposing that, a building has 3 floors, and it was built on a ground which is defined as danger zone 1 . Then the GSS of that building will be measured as 80 . Similarly, if the same building was built as reinforced concrete shear wall frame, then SSS of that building will be measured as 85 . Otherwise, SSS will be measured as 0 for that building.

Table 3 Ground and Structural System Scores

\begin{tabular}{ccccccc}
\hline & \multicolumn{3}{c}{ Ground System Score (GSS) } & \multicolumn{2}{c}{ Structural System Score (SSS) } \\
\cline { 2 - 6 } $\begin{array}{c}\text { Number of } \\
\text { Floors }\end{array}$ & \multicolumn{2}{c}{ Danger Zone } & & $\begin{array}{c}\text { Reinforced } \\
\text { Concrete } \\
\text { Frame (RCF) }\end{array}$ & $\begin{array}{c}\text { Reinforced Con- } \\
\text { crete Shear Wall } \\
\text { Frame (RCSWF) }\end{array}$ \\
\cline { 2 - 6 } & I & II & III & IV & & 100 \\
1,2 & 90 & 120 & 160 & 195 & 0 & 85 \\
3 & 80 & 100 & 140 & 170 & 0 & 75 \\
4 & 70 & 90 & 130 & 160 & 0 & 65 \\
5 & 60 & 80 & 110 & 135 & 0 & 55 \\
6,7 & 50 & 65 & 90 & 110 & 0 & \\
\hline
\end{tabular}


Özcan et al.

Total Score: Total Score indicates what the final assessment result of specific building is and gives information about calculated performance point. The collected data is evaluated, and a total score (TS) is calculated for each building. Total scores are used to determine the risk priorities of the buildings as well. Thus, Total Score in our model is calculated for each building as seen in Equation 1:

$$
\text { Total Score }=\mathrm{GSS}+\sum_{i=1}^{8}\left(\mathrm{Ni}_{\mathbf{i}} * \mathbf{N P} \mathbf{i}\right)+\mathrm{SSS}
$$

where GSS represents ground system score of building, SSS reflects the structural system score of building, Ni denotes the value corresponding to the $i^{\text {th }}$ negativity parameter of building and NPi refers to the score corresponding to the ith negativity parameter of building. In this equation, $i$ is set from 1 to 8 reflecting negativity parameters that are shown in Table 1.

The main aim of this method is to have general overview for the buildings as rapid as possible, therefore broader and more detailed assessment methods can be applied based on data that are gathered from this method if needed.

The next sub-sections describe the methodology of the proposed informative database along with its architecture for building data warehouse, logical model schema and sample SQL queries.

\subsection{Methodology}

There are four architectural processing stages as illustrated in Figure 1. In the first stage, data extracted from various databases are loaded into the staging area [11]. Then data are stored in data staging area for the purpose of cleansing, scrubbing, fixing data errors and transforming into a more normalized standard. In this process, it is necessary for dropping and merging tables, creating or removing columns. The third processing stage is data transferring into the data warehouse. [23] In the last stage, stored data in data warehouse are analyzed and then used for purpose of query, reporting, data mining and decision support to feed end users.

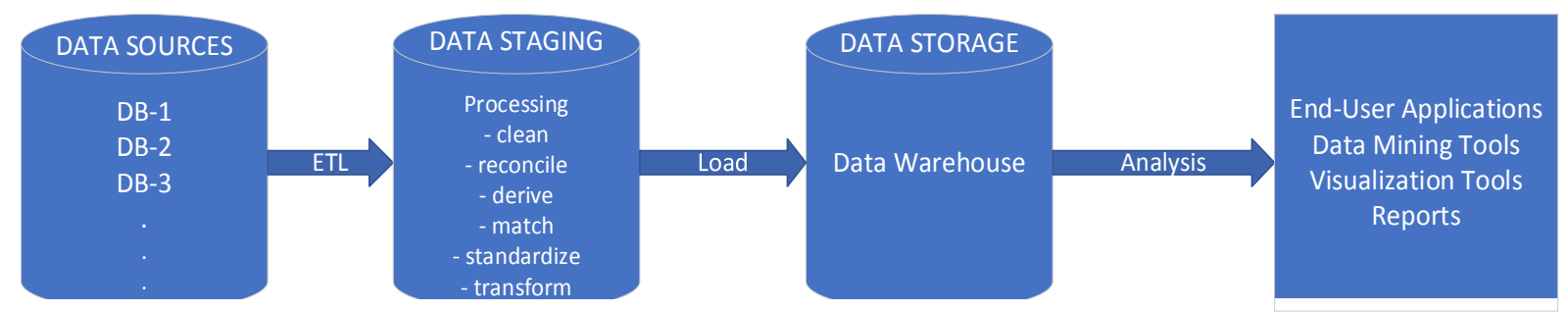

Figure 1 Architecture for Data Warehouse Framework

When designing data warehouses, multidimensional data modeling approaches have been used more often. These approaches enable to store data in a more systematical way. Moreover, they also make the data more useful for operations such as business intelligence, OLAP (On Line Analytical Processing) and data mining processes [15].

Based on the aforementioned issues, the proposed data warehouse is constructed by integrating multiple sources such as relational database systems of Ministry of Health and other public database systems. Finally, the architecture of data warehouse is designed to provide information from historic perspective and nonvolatility.

\subsection{Data Warehouse Design}

The proposed data warehouse has been designed in MS SQL database system. It contains 10 tables and 11 relationships. It contains two facts, Fact_Risk_Assessment and Fact_Facility_Negative_Parameter_Evaluation tables. Each fact table has primary keys and foreign keys for connecting to the dimension tables and a number of measures. The proposed fact constellation schema for "Earthquake Risk Assessment Data Warehouse” is shown in Fig-2. 
Özcan et al.

In the model, it is assumed that all data are cleared, converted to the appropriate format and normalized during the implementation phase. Attributes of the fact and dimension tables are indicative. More attributes can be included in the data warehouse, containing appropriate amount of data for decision-making. Therefore, they are not included in this work for simplification purposes.

In the given dimensional table, it is aimed to collect to identify all healthcare facilities in "Dim_Facility" table so as to analyze the facilities. 'FacilityID' serves as the primary key of the "Dim_Facility" table, which is the unique ID that is provided for each facility and it includes all other information related to the facility. In the "Dim_Facility" table, there are many attributes such as 'Facility_Name', 'Address_ID', 'Facility_Type', 'Number_of_Floors', 'Indoor_Area', 'Number_of_Beds', 'Number_of_Emergency_Beds', 'Care_Level', 'Building_Ownership', 'Establishment_Year', 'Danger Zone' and 'Service_Status' that identifies healthcare facilities separately. The "Dim_Facility” table is also referencing to "Dim_Address" table which stores specific data of related facilities such as address name, district name, city name, seismic zone, population, etc.

“Fact_Facility_Negative_Parameter_Evaluation” represents a part of assessment results and it is directly related to principles published by Ministry of Environment and Urbanization. 'Facility_ID', 'Date_ID', 'Auditor_ID', 'Negative_Parameter_ID' and 'Negative_Parameter_Value' are primary keys of the fact table. It has many to one relationship to two dimension tables; "Dim_Negative_Parameters" and "Dim_Negative_Parameter_Value" dimensions. These two dimensions store various assessment measures and possible values for each parameter that are published by Ministry of Environment and Urbanization. It also refers to 'Dim_Date', 'Dim_Auditor' and 'Dim_Facility' dimension tables in order to answer of the following questions such as 'When did the assessment occurred for each facility?', 'Who did assess for each facility?' and 'Which buildings were assessed?'. Therefore, "Fact_Facility_Negative_Parameter_Evaluation" table is an assessment table in which each result is related to a specific facility. Moreover, the fact here is negative parameter score by date, by auditor, by negative parameter and by negative parameter value.

The second fact is “Fact_Risk_Assessment” table. 'Facility_ID', 'Date_ID' and 'Auditor_ID' are primary keys of the fact table. It is connected to three dimension tables; "Dim_Date”, "Dim_Auditor" and "Dim_Facility". The fact table depicts the assessment scores which would gather all related earthquake risk assessment parameters of healthcare facilities by facility, by date and by auditor. It may be possible not only to obtain total risk assessment scores of the healthcare facilities, but also to carry out wide range of analyzes on related data in the model by using business intelligence, data mining, integration techniques and various queries.

\subsection{Sample Queries}

This section includes sample queries that would run on the proposed data warehouse. Sample queries are presented in Queries 1-5. These queries illustrate how simple extracting statistical information from the proposed data warehouse model is. The sample queries can be performed for various decision processes and they are correspondingly extendable.

a) How is the distribution of healthcare facilities which are in the first-degree seismic zone according to the risk assessment score countrywide?

This query combines data from buildings where in the most dangerous areas of the country. The query is significant for having statistical data analysis based on facility, city and district.

b) How is the distribution of the health facilities in İstanbul according to the risk assessment score in the last ten years?

This query can be used to extract assessment score of buildings where in selected city and selected time period. Even if the query seems to have complexity, it is easy to express by performing five join operations in the fact constellation schema.

c) How many people will not be able to benefited from the healthcare facility which has the highest risk assessment score if it is damaged by an earthquake in the district? 
In this query, a possible situation based on a scenario is considered. The query mentions the possible threat if the building which has the highest risk score cannot be used owing to an earthquake by showing affected population.

d) How is the distribution of attached and rented healthcare facilities which are in the first-degree seismic zone according to negative parameter score?

Earthquake threat may be higher for attached buildings in the most dangerous zone. Therefore, in this query, it is aimed to obtain assessment scores ordered by negative parameter scores and grouped by facility name.

e) What is the average number of risk assessment scores changes for number of floors of healthcare facilities countrywide?

This query considers the average risk assessment scores grouped by number of floors. It has an importance for having a general idea about the relationship between number of floors and risk level of the buildings. This query is thought as significant from the point of prioritizing risky buildings.

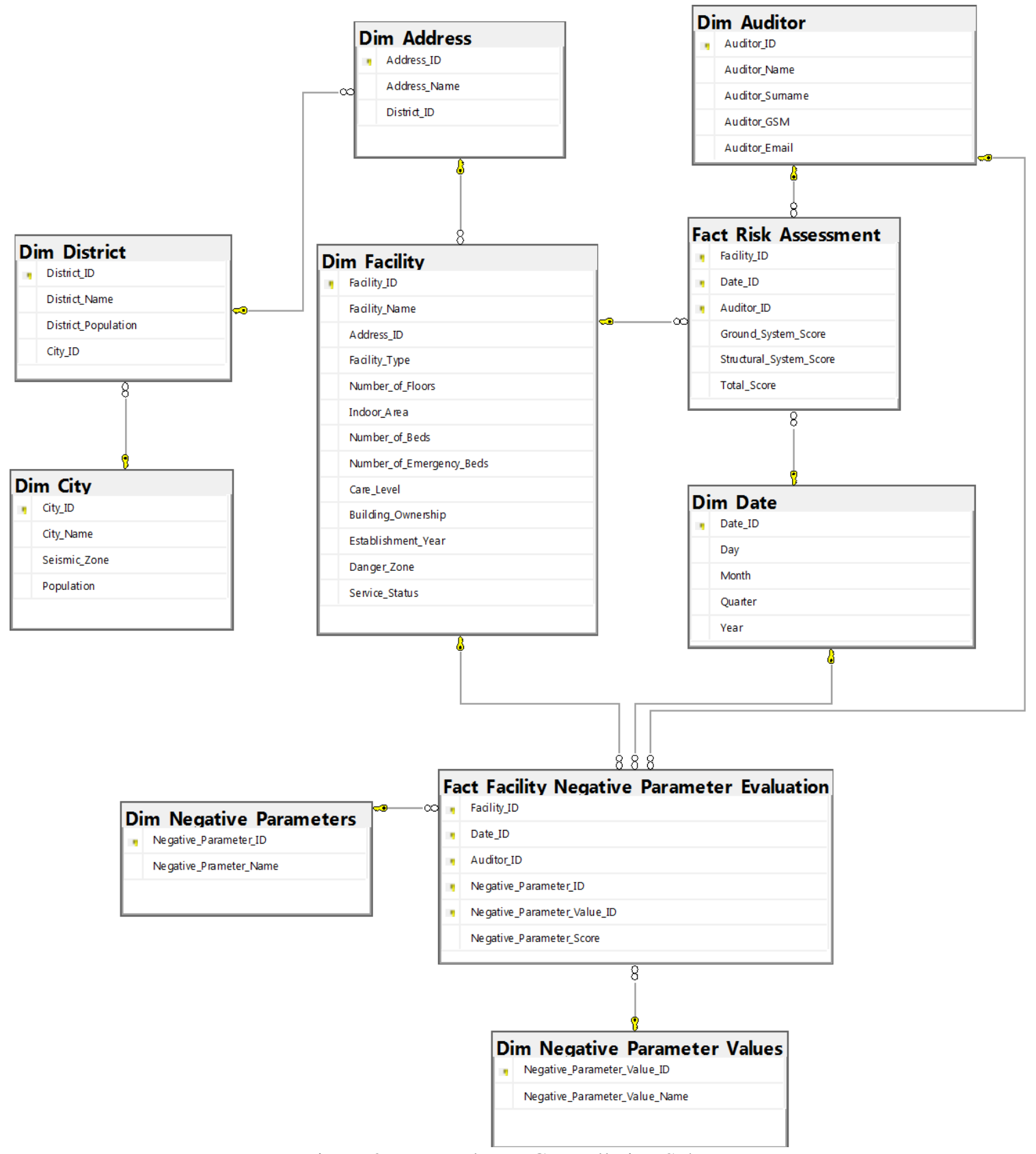

Figure 2 Proposed Fact Constellation Schema 
Query 1

SELECT Facility_Name AS 'Facility Name', City_Name AS 'City', District_Name AS 'District', Total_Score 'Risk Assessment Score' FROM Fact_Risk_Assessment INNER JOIN Dim_Facility ON

Fact_Risk_Assessment.Facility_ID=Dim_Facility.Facility_ID

INNER JOIN Dim_Address ON

Dim_Facility.Address_ID=Dim_Address.Address_ID

INNER JOIN Dim_District ON

Dim_Address.District_ID=Dim_District.District_ID

INNER JOIN Dim_City ON Dim_District.City_ID=Dim_City.City_ID

WHERE Seismic_Zone=1 ORDER BY Total_Score DESC

Query 2

SELECT Facility_Name AS 'Facility Name', Total_Score AS 'Risk

Assessment Score' FROM Fact_Risk_Assessment

INNER JOIN Dim_Facility ON

Fact_Risk_Assessment.Facility_ID=Dim_Facility.Facility_ID

INNER JOIN Dim_Date ON Dim_Date.Date_ID=Fact_Risk_Assessment.Date_ID

INNER JOIN Dim_Address ON

Dim_Facility.Address_ID=Dim_Address .Address_ID

INNER JOIN Dim_District ON

Dim_Address.District_ID=Dim_District.District_ID

INNER JOIN Dim_City ON Dim_District.City_ID=Dim_City.City_ID

WHERE City_Name='İstanbul' and Year BETWEEN 2010 AND 2020

ORDER BY Total_Score DESC

Query 3

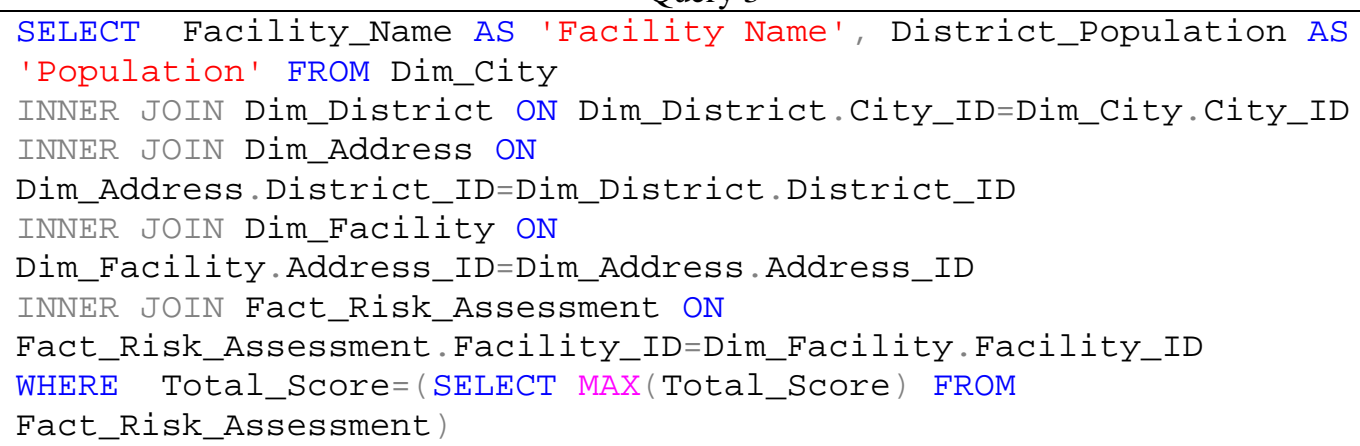

Query 4

\begin{tabular}{|l|l|}
\hline 1 & SELECT Facility_Name AS 'Facility Name', City_Name, \\
2 & SUM(Negative_Parameter_Score) AS 'Score' FROM \\
4 & Fact_Facility_Negative_Parameter_Evaluation \\
5 & INNER JOIN Dim_Facility ON \\
6 & Dim_Facility.Facility_ID=Fact_Facility_Negative_Parameter_Evaluation.F \\
7 & acility_ID \\
8 & INNER JOIN Dim_Address ON \\
9 & Dim_Address.Address_ID=Dim_Facility.Address_ID \\
10 & INER JOIN Dim_District ON \\
11 & INNER JOIN Dim_City ON Dim_City,City_ID=Dim_District.City_ID \\
12 & WHERE Seismic_Zone=1 and Building_OWnership='Rent' and \\
13 & Negative_Parameter_Value_ID BETWEEN 7 AND 10 \\
14 & GROUP BY(Facility_Name) ORDER BY SUM(Negative_Parameter_Score) ASC \\
\hline
\end{tabular}


Özcan et al.

Query 5

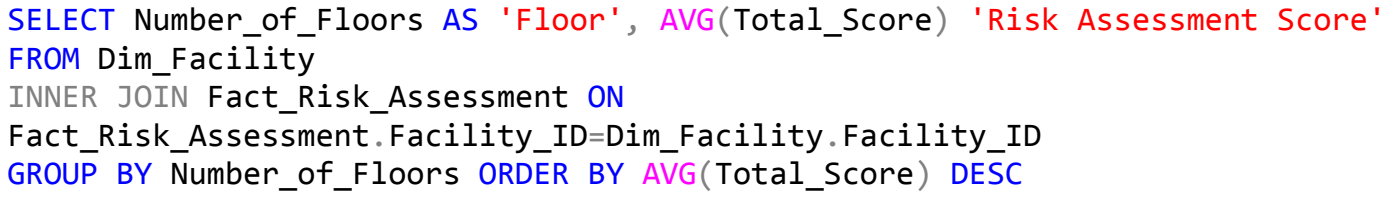

\section{Conclusion}

Earthquake is the fact of life. However, it is known that most of Turkey's cities are considered at moderate or high risk of a major earthquake. With the country becoming ever more urbanized, risk reduction for earthquake is getting a significant long-term problem especially for public authorities who are responsible for taking precautions for the risks of earthquakes. In case of a major earthquake, it is more important for healthcare facilities to survive among public buildings. Previous studies highlight that prioritization should be paid to healthcare facilities. For this reason, there is an urgent need for a comprehensive and systematic assessment of healthcare facilities. In this regard, this study proposes a data warehouse model for assessing risk levels of healthcare buildings in terms of earthquake.

The data warehouse was proposed by taking legislation for risky buildings published by Turkish Environment and Urban Ministry into account. The fact constellation schema model and a multi-dimensional data modeling approach are utilized in the proposed data warehouse. A set of queries were used to illustrate the simplicity of extracting information from the proposed data warehouse. The proposed data warehouse involves an informational database whose data can be extracted from existing operational databases. As far as we know, this study is a first attempt to design a data warehouse for earthquake risk assessment of buildings. It serves a valuable reference for future research in the development of the fact constellation schema for similar purposes. The proposed data warehouse also allows decision makers and policy makers to have more control on the buildings' structural status and risk level in advance.

This paper can be extended in several directions in future research. First, the proposed data warehouse was not implemented, and its performance was not evaluated. In this manner, future research work can focus on the implementation of the proposed design with real data from healthcare facilities. Thus, it can be put into practice and it is possible to compare its performance with a conventional database. Further, it may be useful to adapt the proposed solution to buildings in other domains. Finally, further research might extend the proposed data warehouse design to make it fully compatible with the legislations from different countries.

\section{References}

[1] AFAD, “DDA Catalog,” 2020. https://deprem.afad.gov.tr/ddakatalogu?lang=en (accessed Nov. 30, 2020).

[2] M. M. Önal and S. Çellek, "A Study To Determine The Quality Of Building Stock And Earthquake Risk In Kirsehir,” Int. J. Sci. Technol. Res., vol. 6, no. 4, pp. 105-111, 2017.

[3] A. Ketsap, C. Hansapinyo, N. Kronprasert, and S. Limkatanyu, "Uncertainty and Fuzzy Decisions in Earthquake Risk Evaluation of Buildings,” Eng. J., vol. 23, no. 5, pp. 89-105, 2019, doi: 10.4186/ej.2019.23.5.89.

[4] “OECD Health Statistics,” OECD, 2020. https://stats.oecd.org/viewhtml.aspx?datasetcode=HEALTH_REAC\&lang=en\# (accessed Dec. 11, 2020).

[5] "Health Statistics Yearbook," Ankara, 2018. [Online]. Available: https://dosyamerkez.saglik.gov.tr/Eklenti/39024,haber-bulteni-2019pdf.pdf?0.

[6] G. Garani, A. V. Chernov, I. K. Savvas, and M. A. Butakova, "A Data Warehouse Approach for Business Intelligence," in 28th International Conference on Enabling Technologies: Infrastructure for Collaborative Enterprises, 2019, pp. 70-75, doi: 10.1109/WETICE.2019.00022.

[7] S. H. A. El-Sappagh, A. M. A. Hendawi, and A. H. El Bastawissy, "A proposed model for data 
warehouse ETL processes,” J. King Saud Univ. - Comput. Inf. Sci., vol. 23, no. 2, pp. 91-104, 2011, doi: 10.1016/j.jksuci.2011.05.005.

[8] A. G. P. Kujur and A. Oraon, “A Data Warehouse Design and Usage,” vol. 3, no. 11, pp. 335337, 2016, Accessed: Nov. 29, 2020. [Online]. Available: https://www.academia.edu/34467981/A_Data_Warehouse_Design_and_Usage.

[9] M. Y. Santos, B. Martinho, and C. Costa, "Modelling and implementing big data warehouses for decision support," J. Manag. Anal., vol. 4, no. 2, pp. 111-129, 2017, doi: 10.1080/23270012.2017.1304292.

[10] B. A. Devlin and P. T. Murphy, "An architecture for a Information, business and System," IBM Syst. J., vol. 27, no. 1, pp. 60-80, 1988, doi: 10.1007/978-3-319-77703-0_114.

[11] J. M. Abraham Navamani, A. Kannammal, and P. R. Jeba Thangaiah, "Building multi-dimensional cube to analyze public examination results: A business intelligence approach,” Appl. Mech. Mater., vol. 622, pp. 11-22, 2014, doi: 10.4028/www.scientific.net/AMM.622.11.

[12] I. Güratan, "The Design and Development of a Data Warehouse Using Sales Database and Requirements of a Retail Group,” Dokuz Eylul University, 2005.

[13] D. Moody and M. A. . Kortink, "From Enterprise Models to Dimensional Models: A Methodology for Data Warehouse and Data Mart Design," in Proceedings of the International Workshop on Design and Management of Data Warehouses (DMDW’2000), 2000, pp. 1-12.

[14] D. Moody and M. A. . Kortink, "From Enterprise Models to Dimensional Models: A Methodology for Data Warehouse and Data Mart Design," in International Workshop on Design and Management of Data Warehouses (DMDW'2000), 2000, vol. 28, pp. 1-12.

[15] E. Demir and C. Eren Atay, "Akciğer Kanseri Verilerinin Karar Destek Sistemleri için Veri Ambarında Saklanması," DEU Muhendis. Fak. Fen ve Muhendis., vol. 19, no. 57, pp. 987-997, 2017, doi: 10.21205/deufmd.2017195785.

[16] G. N. A. Dharma, K. O. Saputra, and N. P. Sastra, "Data Warehouse Design for Hospital Executive information using the Facts Constellation Method (Case Study: Bali Mandara Eye Hospital)," vol. 5, no. 2, pp. 6-10, 2020.

[17] S. Asghar, S. Fong, and T. Hussain, "Business intelligence modeling: A case study of disaster management organization in Pakistan," in ICCIT 2009 - 4th International Conference on Computer Sciences and Convergence Information Technology, 2009, pp. 673-678, doi: 10.1109/ICCIT.2009.318.

[18] T. Panrungsri and E. Sangiamkul, "Business intelligence model for disaster management: A case study in Phuket, Thailand," 2017.

[19] K. A. B. Permana, D. A. P. Wulandari, and P. A. Mertasana, "Online Analytical Processing ( OLAP ) for Disaster Report,” Int. J. Eng. Emerg. Technol., vol. 3, no. 1, pp. 26-29, 2018.

[20] E. Işık, M. F. Işıı, and M. A. Bülbül, "BetonarmeBinalarin Web Tabanli HizDeğerlendirilmesi," Uludağ Univ. J. Fac. Eng., vol. 23, no. 1, pp. 225-234, 2018, doi: 10.17482/uumfd.417978.

[21] S. Sarı and T. Türk, "Depremde Meydana Gelebilecek Bina Hasarlarının Coğrafi Bilgi Sistemleri ile İncelenmesi," Türkiye Coğrafi Bilgi Sist. Derg., vol. 2, no. 1, pp. 17-25, 2020, Accessed: Nov. 28, 2020. [Online]. Available: https://dergipark.org.tr/tr/pub/tucbis.

[22] Riskli Yapıların Tespit Edilmesine İlişkin Esaslar. Turkey, 2019, p. 55.

[23] Y. Bassil, “A Data Warehouse Design for a Typical University Information System,” J. Comput. Sci. Res., vol. 1, no. 6, pp. 12-17, 2012. 